\title{
Self-management skills in adolescents with chronic rheumatic disease: A cross-sectional survey
}

Erica F Lawson ${ }^{1 *}$, Aimee O Hersh², Mark A Applebaum ${ }^{1}$, Edward H Yelin ${ }^{3}$, Megumi J Okumura ${ }^{4}$ and Emily von Scheven ${ }^{1}$

\begin{abstract}
Background: For adolescents with a diagnosis of lifelong chronic illness, mastery of self-management skills is a critical component of the transition to adult care. This study aims to examine self-reported medication adherence and self-care skills among adolescents with chronic rheumatic disease.

Methods: Cross-sectional survey of 52 adolescent patients in the Pediatric Rheumatology Clinic at UCSF. Outcome measures were self-reported medication adherence, medication regimen knowledge and independence in health care tasks. Predictors of self-management included age, disease perception, self-care agency, demographics and self-reported health status. Bivariate associations were assessed using the Student's t-test, Wilcoxon rank sum test and Fisher exact test as appropriate. Independence in self-management tasks were compared between subjects age 13-16 and 17-20 using the chi-squared test.

Results: Subjects were age 13-20 years (mean 15.9); 79\% were female. Diagnoses included juvenile idiopathic arthritis (44\%), lupus (35\%), and other rheumatic conditions (21\%). Mean disease duration was 5.3 years (SD 4.0). Fifty four percent reported perfect adherence to medications, 40\% reported 1-2 missed doses per week, and $6 \%$ reported missing 3 or more doses. The most common reason for missing medications was forgetfulness. Among health care tasks, there was an age-related increase in ability to fill prescriptions, schedule appointments, arrange transportation, ask questions of doctors, manage insurance, and recognize symptoms of illness. Ability to take medications as directed, keep a calendar of appointments, and maintain a personal medical file did not improve with age.
\end{abstract}

Conclusions: This study suggests that adolescents with chronic rheumatic disease may need additional support to achieve independence in self-management.

Keywords: Self-management, transition, pediatric rheumatology

\section{Background}

Children with special health care needs (CSHCN), which include children with chronic rheumatologic conditions, typically enter the health care system as passive participants, with parents assuming responsibility for the majority of their health care-related tasks. However, as pediatric patients age into adolescence and young

\footnotetext{
* Correspondence: lawsone@peds.ucsf.edu

'Department of Pediatrics, Division of Rheumatology \& Immunology, University of California, San Francisco, 533 Parnassus, Rm U-127, Box 0107, San Francisco, CA 94143, USA

Full list of author information is available at the end of the article
}

adulthood, there is an expected shift in the burden of responsibility from parent to young adult. Young adults must learn to complete such tasks as scheduling appointments, communicating with providers, securing insurance coverage, and taking medications as directed. Prior studies have shown that CSHCN are often unprepared to make this transition [1,2], leaving them at risk for ongoing dependence on their families and delayed achievement of developmental milestones [3]. While the American Academy of Pediatrics has recommended transition planning for all CSHCN since the 1980s, only $41 \%$ of CSHCN receive transition-planning services [4].
C Biomed Central 
Among young people with juvenile idiopathic arthritis (JIA), studies have shown high rates of unsuccessful transfer to adult care [5]. Many studies have assessed the challenges that $\mathrm{CSHCN}$ face during transition, but evidence-based recommendations to improve transitional care for CSHCN are lacking, and even less is known about the optimal management of rheumatologic disease-specific issues related to transitioning.

Self-management has been defined as an "individual's ability to manage the symptoms, treatment, physical and psychosocial consequences and lifestyle changes inherent in living with a chronic condition" [6]. The development of self-management skills is a critical part of the transition to adulthood for adolescents with a diagnosis of lifelong chronic illness, and failure to develop these skills can prevent successful transition to adult care. Difficulties with self-management in late adolescence and young adulthood may be exacerbated by the transition to new providers and changes in insurance. In most of the United States, public health plans such as Medicaid, SCHIP and the federal Title V program facilitate access to comprehensive health care for CSHCN through age 18 or 21, at which point patients typically "age out" of coverage [7]. Following loss of insurance patients often experience gaps in care, with lapses in doctor visits and medication adherence placing them at risk for increased disease activity and adverse health outcomes [8]. Among patients with rheumatic diseases such as systemic lupus erythematosus and juvenile idiopathic arthritis, ongoing disease activity increases the risk of permanent damage and functional limitation [9]. The problem of poor outcomes in the transition period has been demonstrated in multiple populations $[1,10]$.

Little is known about the self-management skills of adolescents with chronic rheumatic disease, though a recent study showed improved disease knowledge and decreased pain among subjects receiving an internetbased intervention designed to improve self-management in JIA [11]. It is unclear which health care tasks adolescents are completing independently and which tasks they feel unable to complete. While prevalence and causes of medication non-adherence are also not well understood, non-adherence has been associated with poorer health perceptions, self-esteem, mental health, family cohesion, and social functioning [12]. It is unclear whether health-related self-management skills are improving with increasing age, as patients prepare to transfer to adult rheumatology care. Therefore, this cross-sectional study examined self-reported adherence and health-care-related behaviors, as a first step toward assessing health-related self-management among adolescents with rheumatic disease prior to transfer to adultcentered care.

\section{Methods}

\section{Subjects and Data Collection}

We recruited 52 consecutive patients cared for in the Pediatric Rheumatology Clinic at the University of California, San Francisco (UCSF) between February and April of 2009. The UCSF Pediatric Rheumatology Clinic has a wide referral base, caring for patients with a spectrum of rheumatic diseases throughout Northern California. In 2009 there were approximately 1600 outpatient clinic visits. Patients are cared for up to age 21 , at which point they are transferred to adult providers, either at UCSF or in the community.

Criteria for inclusion included age 13 through 20 years, and a confirmed diagnosis of chronic rheumatic disease that would require transition to an adult specialist. Exclusion criteria were inability to speak or read English and cognitive impairment that would prevent future independence in health care management. No compensation for participation was provided. During the recruitment period, 16 patients who met inclusion and exclusion criteria failed to present for a scheduled appointment.

Patients were recruited from all clinic sessions following a convenience sampling strategy. Informed consent was obtained using a protocol approved by the University of California, San Francisco Committee on Human Research. Completion of the visit took approximately 30 minutes and the majority of patients approached agreed to participate. During the recruitment period 87 patients who met inclusion criteria were seen in clinic and 60\% were enrolled. Participants completed a transition-readiness survey that included multiple choice, Likert scale, and free-response questions [13-16]. Subjects completed the surveys at a single clinic visit.

\section{Outcome Measures}

Disease self-management was assessed in two domains: independence in self-management tasks and selfreported medication adherence. Independence in selfmanagement tasks was assessed with a 15-question tool, which was adapted from the California Healthy and Ready to Work Health Care Transition Guide [13]. Subjects were asked to report whether a given health care task was typically completed independently, completed with some assistance, or completed by someone else. Subjects were considered proficient if they could complete a task without any assistance. Health care tasks included carrying an insurance card, refilling prescriptions, and keeping a calendar of appointments. Medication adherence was assessed with 3 multiple-choice questions developed by the investigators. The first asked whether doses of medication were missed. The second assessed frequency of missed doses. The third asked 
why subjects missed doses. Subjects were defined as adherent if they reported taking all doses of their medication in a typical week.

\section{Predictors of Self-Management}

Predictors of interest included medication regimen knowledge, disease perception, self-care agency, demographics, and health status. To assess medication regimen concordance, patients were asked to provide the name, dosing regimen, and purpose for each of their medications. This patient-generated list was compared to the medication list in the clinic note from the day the survey was administered. Concordance for medication names, dosing intervals, and purposes were separately calculated as the percent of correct responses. For example, if a patient was prescribed 3 medications and listed the correct name for 3 , the correct dosing interval for 2 , and the correct purpose for 1 , then concordance for name, dosing interval and purpose would be calculated as $100 \%, 67 \%$ and $33 \%$, respectively. In assessing concordance for medication purpose, responses were scored as correct if answers demonstrated any degree of understanding of medication purpose.

Cognitive and emotional representations of illness were assessed with the Brief Illness Perception Questionnaire (Brief IPQ). Research has demonstrated the importance of illness representations in adaptation to chronic disease [16]. The first 8 questions of the Brief IPQ evaluate independent aspects of illness perception on a 0-10 Likert scale: consequences of illness, expected duration of illness, ability to personally control symptoms, ability of treatment to control symptoms, influence of illness on personal identity, concern about illness, understanding of illness, and emotional response to illness. The Brief IPQ has been validated in populations with diabetes, asthma, renal disease, and minor illnesses. It has been used in both adolescents and adults [14].

Self-care agency has been defined as "the power of an individual to engage in estimative and productive operations essential for self-care" [15]. This was assessed with the Exercise of Self-Care Agency (ESCA), a 35-item selfreport questionnaire on a 5-point Likert scale. Total score ranges from 0-140. Higher scores have been associated with positive health behaviors [15]. The ESCA has been validated in multiple populations, including a cohort of American high school students [17].

Finally, 10 items assessed additional patient and disease characteristics that may mediate disease self-management. Demographics reported included age, gender and race. Disease-related factors included diagnosis and disease duration. Disease activity was assessed on a 0-10 Likert scale. Chart review was performed to confirm self-reported diagnosis and obtain additional diseaserelated data.

\section{Statistical Analysis}

Summary statistics were used to describe all survey domains. Bivariate associations between self-reported medication adherence and other survey measures were assessed using the Student's t-test for normally distributed data, and the Wilcoxon rank-sum test for non-parametric data. Categorical associations were assessed using the Fisher exact test. In order to assess which self-care skills improve with age and which do not, independence in self-management tasks was compared between subjects age 13-16 and 17-20 using the chi-squared test. These age cut points were chosen in order to create groups of older and younger adolescents which could be applied across all measures, reflecting the developmental changes that occur in adolescence. Statistical analysis was performed using Stata version 11 for Macintosh (StataCorp LP, College Station, TX, USA).

\section{Results}

Surveys were completed by 52 subjects (Table 1 ). Patients were $13-20$ years old (mean 15.9) and 79\% were female. Our sample was ethnically diverse: $50 \%$ White, 23\% Asian, 8\% Latino, 6\% African American, and 13\% unknown or other race. Diagnoses included juvenile idiopathic arthritis (44\%), lupus (35\%), dermatomyositis (8\%), mixed connective tissue disease (6\%), scleroderma (4\%), idiopathic thrombocytopenic purpura (2\%), and periodic fever syndrome (2\%). Mean disease duration was 5.3 years (SD 4.0). Subjects took a mean of 3.3 medications (SD 2.0), and 58\% were taking systemic corticosteroids. Mean self-reported disease activity on a 010 Likert scale was 4.1 (SD 2.6). While subjects age 1316 were more likely to take methotrexate than their 17 20 year-old peers, there were no other statistically significant differences in characteristics between age groups.

For the primary outcome measure - independent completion of health care management tasks (Table 2) - the majority of subjects know or carry emergency phone numbers $(80 \%)$, have and know how to use a thermometer (68\%), ask their doctor questions (65\%), know symptoms of illness (63\%), and take medications (63\%). They were less likely to schedule their own medical appointments (17\%), carry insurance information (21\%), maintain a medical file (22\%), get prescriptions filled (25\%), or be aware of future changes in their own health insurance (26\%). As compared to subjects age 13-16, 1720 year olds showed increased ability to fill prescriptions, schedule appointments, arrange transportation to appointments, ask questions of their doctors, carry health insurance information, be aware of future changes in health insurance, and recognize symptoms of illness. However, older subjects were no more proficient than their younger peers at knowing medication names and purposes, taking medications as directed, keeping a 
Table 1 Demographics, disease characteristics and medications.

\begin{tabular}{|c|c|c|}
\hline & $\mathrm{N}(\%)$ & $\begin{array}{c}\text { Mean (SD) } \\
\text { or } \\
\text { Median } \\
\text { (Range) } \\
\end{array}$ \\
\hline \multicolumn{3}{|l|}{ Gender } \\
\hline Male & $\begin{array}{c}11 \\
(21 \%)\end{array}$ & \\
\hline Female & $\begin{array}{c}41 \\
(79 \%)\end{array}$ & \\
\hline Mean age $(S D)^{\#}$ & & $15.9(2.1)$ \\
\hline \multicolumn{3}{|l|}{ Race/Ethnicity } \\
\hline Caucasian & $\begin{array}{c}26 \\
(50 \%)\end{array}$ & \\
\hline Asian & $\begin{array}{c}12 \\
(23 \%)\end{array}$ & \\
\hline Latino & $4(8 \%)$ & \\
\hline African American & $3(6 \%)$ & \\
\hline Other/Unknown & $7(13 \%)$ & \\
\hline \multicolumn{3}{|l|}{ Diagnosis } \\
\hline Juvenile Idiopathic Arthritis & $\begin{array}{c}23 \\
(44 \%)\end{array}$ & \\
\hline Oligoarthritis & $1(2 \%)$ & \\
\hline $\begin{array}{l}\text { Rheumatoid factor positive } \\
\text { polyarthritis }\end{array}$ & $3(6 \%)$ & \\
\hline $\begin{array}{l}\text { Rheumatoid factor negative } \\
\text { polyarthritis }\end{array}$ & $8(15 \%)$ & \\
\hline Systemic arthritis & $8(15 \%)$ & \\
\hline Enthesitis-related arthritis & $2(4 \%)$ & \\
\hline Psoriatic arthritis & $1(2 \%)$ & \\
\hline Systemic Lupus Erythematosus & $\begin{array}{c}18 \\
(35 \%)\end{array}$ & \\
\hline Juvenile Dermatomyositis & $4(8 \%)$ & \\
\hline Mixed Connective Tissue Disease & $3(6 \%)$ & \\
\hline Scleroderma & $2(4 \%)$ & \\
\hline Idiopathic Thrombocytopenic Purpura & $1(2 \%)$ & \\
\hline Periodic Fever Syndrome & $1(2 \%)$ & \\
\hline Median Disease Duration (Range) ${ }^{\#}$ & & $5.3(0-15)$ \\
\hline Mean Self-Reported Disease Activity (SD)* & & $4.1(2.6)$ \\
\hline \multicolumn{3}{|l|}{ Medications } \\
\hline Corticosteroids & $\begin{array}{c}30 \\
(58 \%)\end{array}$ & \\
\hline Methotrexate or Leflunomide & $\begin{array}{c}24 \\
(45 \%)\end{array}$ & \\
\hline Hydroxychloroquine & $\begin{array}{c}19 \\
(37 \%)\end{array}$ & \\
\hline Biologic & $\begin{array}{c}15 \\
(29 \%)\end{array}$ & \\
\hline Immunosuppressant ${ }^{+}$ & $\begin{array}{c}13 \\
(25 \%)\end{array}$ & \\
\hline Intravenous Immunoglobulin & $2(4 \%)$ & \\
\hline Non-Steroidal Anti-Inflammatory Drug & $2(4 \%)$ & \\
\hline
\end{tabular}

calendar, maintaining a personal medical file, using a thermometer or knowing where to obtain contraception (Table 2).

For the secondary outcome measure - medication adherence - 54\% reported perfect adherence, $40 \%$ reported 1-2 missed doses per week, and 6\% reported missing $>3$ doses per week. Reasons for non-adherence included forgetfulness (54\%), running out of medication $(10 \%)$, and intentionally skipping doses (10\%).

Medication concordance was assessed as a predictor of medication adherence. Among all subjects, mean concordance was $89 \%$ (range $25-100 \%$ ) for knowing medication names, $78 \%$ (range $0-100 \%$ ) for knowing the correct dosing regimen, and 54\% (range $0-100 \%$ ) for knowing the purpose of their medications. Concordance for medication purpose fell at two extremes: $35 \%$ of patients were able to describe the purpose of all of their medications and 30\% were not able to state the purpose of any of their medications. The majority of patients use at least one memory aid to help them remember to take their mediations: $58 \%$ use a pill box; $6 \%$ use a timer; and $16 \%$ use other reminders, including cellular phone alarms, keeping bottles visible, and parental reminders. There was no statistically significant association between regimen knowledge or use of medication reminders and self-reported medication adherence (Table 3).

Mean score on the Exercise of Self-Care Agency Scale was 73.2 (SD 16.9), as compared to 89.5 (SD 19.4) for a published report of high school students $(\mathrm{P}<0.001)$ [17]. There was a trend towards lower levels of self-care agency among subjects with higher self-reported adherence $(P=0.07)$. According to the Brief IPQ, most subjects believe medications can effectively treat their illness (7.2) and that they have moderate understanding of their illness (6.7). There were no significant associations between illness perception or other predictors and self-reported adherence.

\section{Discussion}

Our findings provide insight into self-management proficiency and medication adherence among adolescents with chronic rheumatic disease. While this cohort showed good progress towards achieving independence in disease-management tasks in several domains, deficits were evident in other areas. Furthermore, older patients did not demonstrate an increase in proficiency in several areas as compared to their younger peers. Lack of improvement in self-management independence with increasing age suggests that adolescents are not mastering certain skills critical to self-management of chronic illness. Tasks that are most challenging for young patients involve interaction with adult-oriented systems and organizational skills, such as calling a medical office 
Table 2 Independent Completion of Health Care Tasks.

\begin{tabular}{|c|c|c|c|}
\hline & $\begin{array}{l}\text { Age } 13-16 \\
(\mathrm{~N}=31)\end{array}$ & $\begin{array}{l}\text { Age 17-21 } \\
(\mathrm{N}=21)\end{array}$ & $\mathbf{P}$ \\
\hline \multicolumn{4}{|l|}{ Medication Management } \\
\hline Know medication names, purposes and side effects & $15(48 \%)$ & $14(67 \%)$ & 0.26 \\
\hline Take medications as directed & $17(56 \%)$ & $13(62 \%)$ & 0.78 \\
\hline Fill prescriptions & $2(6 \%)$ & $11(52 \%)$ & $<0.001$ \\
\hline \multicolumn{4}{|l|}{ Medical Appointments } \\
\hline Schedule appointments & $2(6 \%)$ & $6(29 \%)$ & 0.05 \\
\hline Keep a calendar of appointments & $12(39 \%)$ & $10(48 \%)$ & 0.58 \\
\hline Arrange transportation to appointments & $4(13 \%)$ & $13(62 \%)$ & 0.001 \\
\hline Prepare and ask questions of your doctor & $16(52 \%)$ & $18(86 \%)$ & 0.02 \\
\hline \multicolumn{4}{|l|}{ Health Insurance and Information Management } \\
\hline Carry health insurance information & $3(10 \%)$ & $8(38 \%)$ & 0.02 \\
\hline Know about future changes in your health insurance & $4(13 \%)$ & $9(43 \%)$ & 0.02 \\
\hline Maintain a personal medical file & $4(13 \%)$ & 7 (33\%) & 0.10 \\
\hline \multicolumn{4}{|l|}{ Other Health Care Skills } \\
\hline Have and know how to use a thermometer & $20(65 \%)$ & $14(67 \%)$ & 1.0 \\
\hline Know symptoms of illness and when to call doctor & $16(52 \%)$ & $17(81 \%)$ & 0.04 \\
\hline Know where to obtain contraception & $11(35 \%)$ & $11(52 \%)$ & 0.26 \\
\hline Know or carry emergency phone numbers & $23(74 \%)$ & $18(85 \%)$ & 0.50 \\
\hline
\end{tabular}

to schedule appointments, keeping a calendar, and maintaining a personal medical file.

While interventions to improve self-management have been shown to improve health outcomes and quality of life in both adults and children [18], these programs are not widely implemented. Data from several studies suggests that patient education interventions for CSHCN can be effective in improving health outcomes and decreasing loss to follow-up in the transition period [19]. Like many institutions, UCSF lacks a formal transition program for adolescents with chronic illness. Patients are expected to master disease self-management skills through parental coaching at home and physician encouragement as a part of routine care. However, our data suggest that this approach is not sufficient to achieve independence in all self-management skills in these older adolescents who are approaching transition.
Approximately half of our patients report imperfect adherence to medications, which is similar to other reported adherence rates among adolescents with chronic illness. The most common reason provided for missing medications was forgetfulness, a finding that has been reported previously [20]. Few subjects admit to intentionally skipping doses of medication, though subjects may be hesitant to disclose intentional non-adherence. Understanding the cause of medication non-adherence is important because while medication reminders may be effective for patients who forget to take their medications, they are unlikely to improve adherence if patients actively choose not to take their medications. Automated medication reminders have been studied extensively among adults with chronic disease, with some evidence of success [21].

Table 3 Contribution of number of medications and medication knowledge to self-reported adherence.

\begin{tabular}{|c|c|c|c|c|}
\hline & $\begin{array}{l}\text { All patients } \\
(\mathrm{N}=52)^{* *}\end{array}$ & $\begin{array}{l}\text { Adherent }^{\#} \\
(\mathrm{~N}=21)\end{array}$ & $\begin{array}{l}\text { Nonadherent }{ }^{\#} \\
(\mathrm{~N}=30)\end{array}$ & $\mathbf{P}$ \\
\hline Number of medications prescribed, mean (SD) & $3.3(2.0)$ & $3.0(2.5)$ & $3.6(1.4)$ & 0.27 \\
\hline Number of patients using medication reminders, $\mathrm{N}$ (percent) & $29(58 \%)$ & $11(55 \%)$ & $18(60 \%)$ & 0.73 \\
\hline Concordance for medication name, mean (range) ${ }^{*}$ & $\begin{array}{c}89 \% \\
(25-100 \%)\end{array}$ & $\begin{array}{c}92 \% \\
(44-100 \%)\end{array}$ & $\begin{array}{c}87 \% \\
(25-100 \%)\end{array}$ & 0.57 \\
\hline Concordance for medication dosing, mean (range) ${ }^{*}$ & $\begin{array}{c}78 \% \\
(0-100 \%)\end{array}$ & $\begin{array}{c}82 \% \\
(0-100 \%)\end{array}$ & $\begin{array}{c}76 \% \\
(25-100 \%)\end{array}$ & 0.39 \\
\hline Concordance for medication purpose, mean (range)* & $\begin{array}{c}54 \% \\
(0-100 \%)\end{array}$ & $\begin{array}{c}50 \% \\
(0-100 \%)\end{array}$ & $\begin{array}{c}56 \% \\
(0-100 \%)\end{array}$ & 0.89 \\
\hline
\end{tabular}

* Concordance was calculated as the number of correct patient responses divided by the total number of medications prescribed, reported as mean (range).

\# Adherence was defined as taking all prescribed doses of medication in a typical week.

** One patient did not report adherence. 
With regard to predictors of self-reported medication adherence, accurately reporting the medication names and dosing regimens did not correlate with adherence. Interestingly, knowledge of medication purpose fell at two extremes, with the majority of patients demonstrating either very good understanding of the indications for their medications, or very poor understanding. It may be that some subjects have not been sufficiently engaged in their medical care or have not been willing to engage, and therefore lack understanding of the purposes of their medications. Other patients with pediatric-onset disease may have not be aware of the purpose of medications that they have taken since early childhood, when information about medications was directed towards the parent rather than the patient.

This study has several important limitations. Our results are derived from English-speaking patients at a single U.S. center and thus may not be generalizable to all practices. However, since UCSF is a Title V referral site, this study does draw from a diverse patient population representing Northern California. While subjects were recruited consecutively, our population may be biased towards more adherent patients, since those who did not appear for their appointments did not have the opportunity to participate in the study. Data on adherence and self-care practices were obtained via selfreport, which is simple and cost-effective but may be subject to recall bias and social desirability bias [22]. In addition, the adherence measures used were developed by the authors and not tested prior to use. Our sample size was also small; however, rheumatic diseases in children are relatively rare. Finally, quantitative analysis may not be able to fully and accurately describe complex behavior around adherence.

\section{Conclusions}

Transition to adulthood is an exciting and a challenging time, when adolescents and young adults must complete many educational, social, and vocational tasks. For adolescents with a diagnosis of lifelong chronic illness, mastering disease self-management is a critical part of this transition. This study suggests that the current standard of care is inadequate to prepare adolescents to successfully manage their disease in adulthood. Further work is needed to assess deficits in self-care skills in a broader population of adolescents with rheumatic disease to ensure generalizability of the current findings, which can then be applied to the development of targeted self-care improvement programs. Interventions to improve self-management should be integrated into standardized transition readiness procedures that address both the self-management and health care systems aspects of transition to adult care, and ultimately lead to improved health outcomes.

\section{Acknowledgements}

This work was supported by a Picker Challenge Grant from the Accreditation Council for Graduate Medical Education.

\section{Author details}

'Department of Pediatrics, Division of Rheumatology \& Immunology, University of California, San Francisco, 533 Parnassus, Rm U-127, Box 0107, San Francisco, CA 94143, USA. ²Department of Pediatrics, Division of Allergy, Immunology \& Rheumatology, University of Utah, 295 Chipeta Way, Salt Lake City, UT 84108, USA. ${ }^{3}$ Department of Medicine, Division of Rheumatology, University of California, San Francisco, 3333 California Street, Suite 270, San Francisco, CA 94143-0920, USA. Department of Pediatrics, Division of General Pediatrics, University of California, San Francisco, 3333 California Street, Suite 245, San Francisco, CA 94118, USA.

\section{Authors' contributions}

EFL performed the statistical analysis and drafted the manuscript. $\mathrm{AOH}$ conceived the study, designed the survey, and participated in data interpretation and manuscript compilation. MAA, EHY and MJO participated in data interpretation and manuscript compilation. EVS conceived the study, and participated in its design and coordination and helped to draft the manuscript. All authors read and approved the final manuscript.

\section{Competing interests}

The authors declare that they have no competing interests.

Received: 31 August 2011 Accepted: 6 December 2011 Published: 6 December 2011

\section{References}

1. McDonagh JE, Kelly DA: The challenges and opportunities for transitional care research. Pediatric transplantation 2010, 14:688-700.

2. Stinson JN, Toomey PC, Stevens BJ, Kagan S, Duffy CM, Huber A, Malleson P, McGrath PJ, Yeung RS, Feldman BM: Asking the experts: exploring the self-management needs of adolescents with arthritis. Arthritis Rheum 2008, 59:65-72.

3. Stam H, Hartman EE, Deurloo JA, Groothoff J, Grootenhuis MA: Young adult patients with a history of pediatric disease: impact on course of life and transition into adulthood. The Journal of adolescent health: official publication of the Society for Adolescent Medicine 2006, 39:4-13.

4. Lotstein DS, Ghandour R, Cash A, McGuire E, Strickland B, Newacheck P: Planning for health care transitions: results from the 2005-2006 National Survey of Children With Special Health Care Needs. Pediatrics 2009, 123: e145-152.

5. Hazel E, Zhang X, Duffy CM, Campillo S: High rates of unsuccessful transfer to adult care among young adults with juvenile idiopathic arthritis. Pediatr Rheumatol Online J 2010, 8:2.

6. Barlow J, Wright C, Sheasby J, Turner A, Hainsworth J: Self-management approaches for people with chronic conditions: a review. Patient Educ Couns 2002, 48:177-187.

7. Nicholson JL, Collins SR, Mahato B, Gould E, Schoen C, Rustgi SD: Rite of passage? Why young adults become uninsured and how new policies can help, 2009 update. Issue Brief (Commonw Fund) 2009, 64:1-20.

8. Lotstein DS, Inkelas M, Hays RD, Halfon N, Brook R: Access to care for youth with special health care needs in the transition to adulthood. The Journal of adolescent health: official publication of the Society for Adolescent Medicine 2008, 43:23-29.

9. Kamphuis S, Silverman ED: Prevalence and burden of pediatric-onset systemic lupus erythematosus. Nature reviews Rheumatology 2010, 6:538-546.

10. Hersh AO, Pang S, Curran ML, Milojevic DS, von Scheven E: The challenges of transferring chronic illness patients to adult care: reflections from pediatric and adult rheumatology at a US academic center. Pediatric rheumatology online journal 2009, 7:13.

11. Stinson JN, McGrath PJ, Hodnett ED, Feldman BM, Duffy CM, Huber AM, Tucker LB, Hetherington CR, Tse SML, Spiegel LR, Campillo S, Gill NK, White ME: An Internet-based Self-management Program with Telephone Support for Adolescents with Arthritis: A Pilot Randomized Controlled Trial. J Rheumatol 2010. 
12. Fredericks EM, Magee JC, Opipari-Arrigan L, Shieck V, Well A, Lopez MJ: Adherence and health-related quality of life in adolescent liver transplant recipients. Pediatric transplantation 2008, 12:289-299.

13. Betz CL: California healthy and ready to work transition health care guide: developmental guidelines for teaching health care self-care skills to children. Issues in comprehensive pediatric nursing 2000, 23:203-244.

14. Broadbent E, Petrie KJ, Main J, Weinman J: The brief illness perception questionnaire. Journal of psychosomatic research 2006, 60:631-637.

15. Kearney BY, Fleischer BJ: Development of an instrument to measure exercise of self-care agency. Research in nursing \& health 1979, 2:25-34.

16. Stanton AL, Revenson TA, Tennen H: Health psychology: psychological adjustment to chronic disease. Annual Review of Psychology 2007, 58:565-592.

17. Callaghan DM: The influence of spiritual growth on adolescents' initiative and responsibility for self-care. Pediatric nursing 2005, 31:91-95, 115.

18. Stinson J, Wilson R, Gill N, Yamada J, Holt J: A systematic review of internet-based self-management interventions for youth with health conditions. J Pediatr Psychol 2009, 34:495-510.

19. Crowley R, Wolfe I, Lock K, McKee M: Improving the transition between paediatric and adult healthcare: a systematic review. Arch Dis Child 2011, 96:548-553.

20. Shemesh E, Shneider BL, Savitzky JK, Arnott L, Gondolesi GE, Krieger NR, Kerkar N, Magid MS, Stuber ML, Schmeidler J, Yehuda R, Emre S: Medication adherence in pediatric and adolescent liver transplant recipients. Pediatrics 2004, 113:825-832.

21. Haynes RB, Ackloo E, Sahota N, McDonald HP, Yao X: Interventions for enhancing medication adherence. Cochrane database of systematic reviews (Online) 2008, 2:CD000011.

22. Osterberg L, Blaschke T: Adherence to medication. The New England journal of medicine 2005, 353:487-497.

doi:10.1186/1546-0096-9-35

Cite this article as: Lawson et al: Self-management skills in adolescents with chronic rheumatic disease: A cross-sectional survey. Pediatric Rheumatology 2011 9:35.

\section{Submit your next manuscript to BioMed Central} and take full advantage of:

- Convenient online submission

- Thorough peer review

- No space constraints or color figure charges

- Immediate publication on acceptance

- Inclusion in PubMed, CAS, Scopus and Google Scholar

- Research which is freely available for redistribution

Submit your manuscript at www.biomedcentral.com/submit
Biomed Central 